\title{
El pueblo español en el lienzo de plata: nación y región en el cine de la II República
}

\author{
Marta García Carrión ${ }^{1}$ \\ Universidad de Valencia
}

RESUMEN: El artículo plantea una reflexión sobre la presencia y alcance de los discursos del nacionalismo español en la cultura de masas a partir del estudio del cine español producido durante los años de la II República. A partir de una perspectiva basada en los más recientes desarrollos teóricos sobre el nacionalismo, y particularmente aquellos relativos al papel del mundo de la cultura, el artículo pretende situar al cine en el centro del estudio del proceso de construcción de la identidad nacional española en las primeras décadas del siglo XX. El eje analítico será el examen de la construcción cinematográfica de los imaginarios regionales como representación de España. Tras unas consideraciones generales relativas a la presencia de los imaginarios regionales y nacionales en la cinematografía española, el artículo se centrará concretamente en el análisis de la elaboración fílmica de los imaginarios de las regiones de Andalucía y Aragón, a partir del estudio detallado de algunos de los filmes españoles de los años de la II República más representativos. Además del análisis fílmico, se tendrá en cuenta también la recepción crítica de dichos filmes en la prensa especializada y su impacto social.

\section{PALABRAS CLAVE: Nacionalismo español; Imaginarios regionales;} Historia y cine; Cine español; Historia cultural.

\section{Spanish People on the Silver Screen: Nation and Region in the Cinema of the Se- cond Republic}

ABSTRACT: The article reflects on the presence and scope of the discourses of Spanish nationalism in the mass culture through the study of Spanish cinema

1 La autora participa del proyecto de investigación «De la dictadura nacionalista a la España democrática de las autonomías: política, cultura, identidades colectivas» (HAR2011-27392). 
produced during the years of the Second Republic. From a theoretical perspective based on the latest theoretical developments on nationalism, and particularly those concerning the role of culture, the article seeks to place the cinema in the heart of the study of Spanish nation-building process in the first decades of the twentieth century. The analytical axis will be the examination of the filmic construction of the regional imaginaries as a representation of Spain. After some general considerations concerning the presence of regional and national imaginaries in Spanish cinema, the article will focus specifically on the analysis of the filmic production of imaginaries related to the regions of Andalusia and Aragon from the detailed study of some representative films from the years of the Second Republic. In addition to film analysis, it will be also taken into account the critical reception of these films in the press and their social impact.

\title{
KEY WORDS: Spanish nationalism; Regional imaginaries; History and cinema; Spanish cinema; Cultural history.
}

\begin{abstract}
España puede y debe hacer su propaganda cinematográfica - la de sus monumentos y bellezas naturales, la de la alta espiritualidad de nuestra raza, la de su nuevo régimen político, la de su organización, ideales y hombres representativos$\ldots^{2}$
\end{abstract}

Con estas palabras exponía su convicción en la labor patriótica que el cinematógrafo debía desarrollar Ricardo Urgoiti, fundador de Filmófono, pocos meses antes de que esta compañía comenzara su actividad de producción cinematográfica. En marzo de 1936, la casa Cifesa, que llevaba ya dos años produciendo películas con éxito, explicaba que siempre se servía para dotar de contenido a sus películas «de los varios aspectos y temas que ofrece la historia, la literatura, el arte y el alma hispánica», con el objetivo de «prestigiar al cine nacional y a España» ${ }^{3}$.

Filmófono y Cifesa fueron las dos productoras de cine españolas más importantes durante la II República. A pesar de las diferencias ideológicas entre sus propietarios (mientras Urgoiti, promotor de Unión Radio, mantuvo siempre una filiación liberal, y en su productora ocuparon un puesto destacado personajes de tendencias ideológicas de izquierdas como Eduardo Ugarte y Luis Buñuel, los Casanova estaban vinculados a la Derecha Regional Valenciana ${ }^{4}$ ), ambas empresas mantuvieron una política de producción bastante similar: películas de importante presupuesto y calidad técnica, fomento de un star system español y, sobre todo, argumentos de temática popular y española. Este último aspecto era clave, hasta el punto que no se puede entender la ci-

2 Anuario cinematográfico español. 1935: 14.

3 Noticiero Cifesa 14 (marzo 1936).

4 FERNÁNDEZ COLORADO y CERDÁN, 2007. FANÉS, 1989. 
nematografía española del periodo sin tener en cuenta la centralidad de la preocupación por crear un cine nacional que diera cuenta de la idiosincrasia española. Lo cierto es que este interés por crear un «cine nacional», una cinematografía que respondiera y trasladara al séptimo arte las «esencias» nacionales, no fue una peculiaridad española, sino de una característica de las cinematografías europeas del momento ${ }^{5}$. El lienzo de plata, como se llamaba a la pantalla cinematográfica, se llenó así de relatos e imágenes sobre España y lo que se entendían como sus peculiaridades y esencias distintivas.

Este artículo plantea abordar, desde la historia cultural, el análisis del discurso nacionalista sobre España y sus regiones presentes en esas narraciones fílmicas. El objetivo de este análisis es situar al cine en el corazón de la reflexión en torno al proceso de construcción de la identidad nacional en el siglo XX español, concretamente en los años treinta, así como en la consideración del papel jugado por los imaginarios regionales en la elaboración y difusión de narraciones sobre la identidad española. En el análisis que planteamos sobre la elaboración cinematográfica de las regiones trazaremos también la presencia constante de un discurso sobre «lo popular» que actúa como piedra de toque a la hora de fijar la «autenticidad» de la representación nacional realizada a través de lo regional.

\section{CINE Y NACIÓN: PERSPECTIVAS HISTORIOGRÁFICAS}

Desde la década de los noventa, la historiografía ha situado el mundo de la cultura en el centro de la reflexión sobre el nacionalismo y sus discursos 6 . Ya el trabajo de Benedict Anderson subrayaba que las naciones son construidas a través de procesos de creación de representaciones imaginarias ${ }^{7}$. La construcción del imaginario de una nación supone más que la reunión de un repertorio de referencias simbólicas, incluye su despliegue dentro de un marco de tipo narrativo que confiere a la nación una existencia estable en el tiempo y el espacio $^{8}$. Y es precisamente el ámbito de la definición cultural lo que constituye el territorio, siempre inestable y cambiante, para la discusión y consolidación de las narrativas de la nación ${ }^{9}$.

5 Sobre ello véase GAUTHIER, 51/4 (París, 2004). Algunos estudios de caso sobre cómo se planteó la relación entre la producción cinematográfica y la identidad nacional en HIGSON, 1995. HAYWARD, 2005. HAKE, 2002. 2010.

6 ELEY y SUNY, 1996. Una revision de las teorías sobre el nacionalismo en ÖZKIRIMLI,

7 ANDERSON, 1993.

8 CUBITT, 1998.

9 Como ha señalado Homi Bhabha, el discurso nacionalista no se cierra nunca, está en constante refundación, v. Bhabha Homi, "Introduction: narrating the nation”, en: HOMI 1990. 
A partir de estas perspectivas, el cine, como medio generador de narraciones destinadas a un público masivo, se convierte en un objeto de estudio de enorme interés para analizar los procesos de construcción nacional y los discursos nacionalistas, si bien la atención que le ha prestado la historiografía sobre nacionalismo ha sido más bien escasa. Desde el ámbito de conocimiento de los estudios fílmicos se ha criticado en ocasiones que la influyente perspectiva introducida por Anderson se basaba excesivamente en la cultura impresa y no planteaba una reflexión igualmente elaborada sobre cómo se imagina esa comunidad nacional en otros medios ${ }^{10}$. Por otra parte, Tim Edensor ha señalado que los principales teóricos sobre nacionalismo han mantenido una concepción un tanto estática de la cultura, centrándose en la cultura alta y oficial y dejando fuera otras manifestaciones culturales presentes en la vida cotidiana ${ }^{11}$. Una crítica análoga puede aplicarse a los estudios sobre los discursos nacionalistas y la identidad nacional española durante el siglo XX, en los que, por ejemplo, la cultura de masas está ausente o relegada a un breve comentario. Los principales estudios sobre los discursos del nacionalismo español o bien han analizado los lenguajes explícitamente políticos o bien se han centrado en la labor de intelectuales y escritores y no en otros materiales culturales ${ }^{12}$. El cine ha quedado, así, fuera de los principales debates y análisis sobre la identidad nacional española, y solo desde el ámbito de trabajo de los estudios cinematográficos se han realizado algunas aproximaciones a la cuestión.

Los escasos trabajos que han abordado explícitamente la relación del cine con el nacionalismo español, como los de Nuria Triana-Toribio o Jean-Claude Seguin, han visto su análisis fuertemente limitado por una comprensión del nacionalismo centrada en las prácticas institucionales que buscan definir e imponer una identidad políticamente funcional ${ }^{13}$. Así, la investigación de Triana Toribio le lleva a apuntar que el cine español en los años veinte y treinta trató de erigir una identidad distintiva basada en la españolidad, pero, sin embargo, no considera que esta filmografía jugara ningún papel nacionalizador por tratarse de una cuestión comercial más que de una política naciona-

Un desarrollo de la relación entre nación y narración aplicada a diversos materiales culturales en BERGER, ERIKSONAS y MYCOCK, 2008.

10 ALTMAN, 1999: 195 y ss. WILLIAMS, 2002: 1-22. SCHLESINGER, 2000.

11 EDENSOR, 2002.

12 Véase en este sentido los trabajos de referencia FOX, 1997. VARELA, 1999. SAZ, 2003. Como excepciones de trabajos que incluyen una reflexión sobre elementos de la cultura popular, ver SERRANO, 1999. FUSI, 2000, 189-196.

13 TRIANA TORIBIO, 2003. SEGUIN, 2007. A ello habría que añadir que en ambos trabajos asumen de forma acrítica la interpretación del proceso de nation-building español como un fracaso, una perspectiva que, si bien dominó el panorama historiográfico la década pasada, ya hace años que viene siendo discutida (ARCHILÉS y MARTÍ, 2002). Actualmente es sometida a amplia crítica incluso por quienes la aceptaban con anterioridad, ver MORENO, 2007. 
lista consciente. Se explicite o no, esta noción teórica «institucionalista» determina unos análisis reductores de los complejos procesos de naturalización de las identidades colectivas. El desarrollo y la expansión del discurso nacionalista no es reducible a la acción del estado o a la manipulación política, tiene una significación propia, ya que aparece en contextos culturales que no están definidos directamente por proyectos de creación del estado-nación ${ }^{14}$. El nacionalismo debe ser conceptualizado como una formación discursiva, una forma particular de ver e interpretar el mundo, un marco de referencia que nos ayuda a dar sentido y a estructurar la realidad que nos rodea ${ }^{15}$. Es más que una doctrina política, una forma de pensar más básica que afecta a la visión completa del mundo y, por tanto, está presente y afecta a muchos más aspectos de la vida social, incluso de la cotidianeidad ${ }^{16}$.

Este artículo propone que en lugar de fijar la atención únicamente en la utilización del cinematógrafo por parte del Estado u otros agentes políticos como instrumento nacionalizador (sin dejar de lado, por supuesto, esta dimensión) se plantee una perspectiva que aborde directamente el análisis (discursivo) del cine, considerando sus mecanismos expresivos específicos, en relación con la narración de la nación española. En nuestra opinión, el hecho de que sean empresas privadas (como las ya citadas Filmófono y Cifesa) las que produzcan filmes de contenido españolista con un fin comercial y no político no supone que estos no pudieran jugar un papel nacionalizador; de hecho, el que se verifique como una estrategia con gran éxito de público ratifica todo lo contrario.

\section{LAS REGIONES COMO REPRESENTACIÓN NACIONAL Y ESPACIO CINEMATO- GRÁFICO}

Es imposible hablar de la cinematografía española de los años republicanos como un todo sin caer en una visión simplificadora y reduccionista ${ }^{17}$. Así, analizar el conjunto de filmografía y de la cultura cinematográfica que vio la luz en los años de la II República requiere un estudio más amplio del planteado en este artículo. Lo que vamos a plantear en las páginas siguientes es un examen del discurso nacionalista español en el cine del periodo republicano

14 CALHOUN, 2008.

15 ÖZKIRIMLI, 2005.

16 BILLIG, 2006.

17 Sobre el cine español de la II República, los trabajos de referencia son las obras ya clásicas de GUBERN, 1977. (Una síntesis posterior en GUBERN, 1995. CAPARRÓS, 1997 y CAPARRÓS, 1981. Solo muy recientemente la historiografía cinematográfica se ha planteado una revisión del periodo, v. Aurora y melancolía. Actas del XIII Congreso de la Asociación Española de Historiadores del Cine. 
tomando como eje analítico la región, un ámbito identitario y de representación clave en el imaginario nacional.

El proceso de construcción de las identidades regionales ha desempeñado históricamente un papel medular en la socialización en la identidad española ${ }^{18}$. En este sentido, el caso español no puede considerarse una anomalía en el contexto europeo del primer tercio del siglo XX. En palabras de Eric Storm, en las décadas anteriores a 1945 el regionalismo fue el traje con el que el ampliamente aceptado discurso del Volksgeist fue vestido, y es casi imposible entender los desarrollos culturales del periodo sin tomar en consideración su profunda y omnipresente influencia ${ }^{19}$. Desde la última década del XIX la región, con sus peculiaridades características, dejó de ser un tema exclusivo de estudiosos y sociedades culturales minoritarias y pasó a ser un movimiento de masas a través de diversas formas de expresión y sociabilidad. El periodo de entreguerras se convirtió en la edad de oro de la cultura popular regionalista, además de influir en la alta cultura y algunos movimientos de vanguardia.

Para el caso español, diversos estudios han apuntado que los años de la Restauración son claves en el proceso de imaginación de la región, en los que desde la literatura, la música o el arte a los discursos científicos se regionali$\mathrm{za}^{20}$. En los años veinte los regionalismos estéticos continuaron y la dictadura de Primo de Rivera potenció las identidades regionales como forma de nacionalismo español ${ }^{21}$. X. M. Núñez Seixas ha apuntado la presencia de los imaginarios regionales durante la guerra civil en los discursos nacionalistas de ambos bandos y su empleo como mito movilizador ${ }^{22}$. También los primeros años del franquismo se caracterizaron por una amplia invocación de los discursos regionales para movilizar el apoyo popular y consolidar el régimen, con el doble propósito de reforzar la identificación de los ámbitos locales con la nación y minar la dinámica política de los nacionalismos no españoles ${ }^{23}$. Así, si durante la dictadura el regionalismo fue reprimido a nivel político hasta, al menos, mediados de los sesenta, en el ámbito cultural se promocionaron, con una clara carga ideológica, los folclores regionales y otros rasgos identitarios como las lenguas.

Pero, ¿y durante la II República? A partir del proceso que se acaba de describir, sería sorprendente que los imaginarios y discursos regionales hubieran desaparecido repentinamente de la cultura española para activarse de nuevo

18 NÚÑEZ SEIXAS, 15/3 (Londres, 2001). ARCHILÉS y MARTÍ, 48 (Valencia, 2004).

19 STORM, 33/2 (Londres, 2003). STORM, 2010.

20 MAINER, 1993. ARCHILÉS, 74/4 (Madrid, 2006). VILLARES, 2009.

21 Un aspecto, sin embargo, ausente en la mejor investigación que se ha hecho sobre los procesos de nacionalización durante la dictadura de Primo de Rivera, QUIROGA, 2008.

22 NÚÑEZ SEIXAS, 2006.

23 NÚÑEZ SEIXAS, 15/3 (Budapest, 2008): 299 y ss. 
con posterioridad. Sin embargo, no contamos con estudios monográficos sobre ello, y en los (por otra parte muy escasos) trabajos sobre nacionalismo español en el periodo republicano esta dimensión es completamente obvia$\mathrm{da}^{24}$. El cine, que en los años treinta era uno de los espectáculos más arraigados en los hábitos de ocio de los españoles, nos plantea un campo de estudio de enorme interés para analizar la presencia de los imaginarios regionales en la cultura de masas y su eficacia como discurso nacionalizador. Además, el moderno medio fílmico recogió y entró en diálogo con una serie de materiales como el sainete, la zarzuela o la canción, convirtiéndose así en un componente clave para la comprensión y redefinición de la cultura popular española.

La representación de lo regional puede rastrearse desde los comienzos del cine en España. No obstante, los años veinte fueron un momento especialmente destacado en cuanto a la presencia de imaginarios regionales en el cine español. En este sentido, el cine español de la década estuvo plagado de elaboraciones cinematográficas de las regiones ${ }^{25}$. Así, por la pantalla desfilaron costumbrismos regionales como el asturiano (Bajo las nieblas de Asturias, M. Noriega, 1926; Carolina, la neña de plata, J. Codornié, 1927), gallego (Maruxa, H. Vorins, 1923; Carmiña, flor de Galicia, R. Lupo, 1926); vasco (El mayorazgo de Basterretxe, M. Azkona, 1928), madrileño (La verbena de la Paloma, J. Buchs, 1921; La revoltosa, F. Rey, 1924), catalán (La tía Ramona, N. Winter, 1927), mallorquín (El secreto de la Pedriza, J. y A. Vázquez, 1926), canario (La hija del mestre, C. L. Monzón, F. González, 1927) o valenciano (Nit d'albaes, M. Thous, 1925; Les barraques, M. Roncoroni, 1925). Estos ejemplos corresponden al cine de ficción, pero cabría tener en cuenta asimismo la realización de documentales que exploran las regiones, muchos de ellos con fines turísticos ${ }^{26}$. Por otra parte, la vindicación de los imaginarios regionales como representación de España fue un discurso de entidad en los debates presentes en la cultura y la crítica cinematográfica de los años veinte sobre qué temas debía tratar el cine nacional.

En la década de los treinta la producción cinematográfica en España siguió unas líneas creativas e industriales muy similares a las desarrolladas en el decenio anterior. A pesar de que con el cambio de década se produjeron dos cambios de gran calado, uno en términos políticos, la proclamación de la II República, y otro en relación con la técnica cinematográfica, la consolidación

24 Es el caso de HOLGUIN, 2002.

25 CÁNOVAS, 1998.

26 Según ha señalado Antonia del Rey, la tendencia a utilizar el documental cinematográfico como medio para exhibir las bellezas españolas, presente desde principios de siglo, se convirtió en los años veinte en una estrategia asumida y planificada tanto de forma institucional como particular, y bailes, rituales, costumbres o paisajes de cada región fueron llevados a la pantalla. DEL REY, 2007. 
del cine sonoro, puede señalarse una notable continuidad en relación con los géneros y temáticas abordadas por el cine español. De hecho, en los años de la II República fueron muy frecuentes los remakes de filmes de los años veinte. Una valoración global de los argumentos de las películas producidas durante los años de la República nos indica la cuantiosa presencia de las temáticas y espacios regionales ${ }^{27}$. Como apuntábamos antes, la cinematografía española del momento (no solo los cineastas o productores, sino también los críticos y comentaristas ${ }^{28}$ ) estuvo muy concernida con la creación de un «cine nacional», una producción fílmica que respondiera al carácter español ${ }^{29}$. En este sentido, la elección de las regiones como espacio narrativo para los filmes nos indica ya un reconocimiento de su idoneidad como encarnación de la idiosincrasia nacional y representación de España. Asimismo, al igual que se señalaba para los años veinte, cabría analizar en profundidad el papel jugado por la producción documental. En conjunto, puede afirmarse que el peso que tuvo la imaginación fílmica de España a partir de las diferentes regiones durante los años treinta fue notable. Además, aunque elementos como la música y los cantos regionales estuvieron presentes en las películas mudas, el cine sonoro permitía darles una expresión acabada y un papel narrativo de mayor relieve.

Tal vez resulte sorprendente que, por otra parte, fueran muy escasas las manifestaciones cinematográficas promovidas por los nacionalismos no españoles. Lo cierto es que apenas podría citarse algún ejemplo aislado en el que el imaginario territorializado o el folclore fuera empleado con un sentido identitario diferente al español. Es el caso del documental Euzkadi (T. Erandorena, 1933), promovido por el Partido Nacionalista Vasco, aunque realizado y financiado casi íntegramente por su director ${ }^{30}$. Pueden destacarse asimismo las actividades de la productora con inquietudes galleguistas Folk, que elaboró noticiarios y documentales, entre los que destaca Hacia una Galicia mejor/Por unha Galicia nova (R. Barreiro, 1933), realizado en el marco de la campaña por el estatuto de autonomía ${ }^{31}$. En Cataluña cabría destacar un caso

27 HEININK y VALLEJO, 2009.

28 Los discursos teóricos y críticos forman una parte esencial en la historia cultural del cine (v. DE BAECQUE, 2003 y su estudio es imprescindible para analizar el funcionamiento de las películas en el espacio público. Algunas consideraciones sobre los vínculos entre crítica cinematográfica y nacionalismo en diversos trabajos de HJORT y MACKENZIE, 2000. BERTHIER 2007. Sobre la presencia del nacionalismo en la cultura cinematográfica española del periodo, ver GARCÍA CARRIÓN, Marta, 2007.

29 GARCÍA CARRIÓN, 2007.

30 Según parece, esta película fue destruida por las fuerzas franquistas poco después de su entrada en San Sebastián. Puede consultarse una reconstrucción aproximada del contenido del film y su historia en ZUNZUNEGUI, 1983.

31 Sobre la productora Folk, v. NOGUEIRA, 2004: 150 y ss. QUIROGA, 1998. 
peculiar, el de El café de la marina (D. Pruna, 1934), film del que se realizaron versiones en español y en catalán. La película contó en su estreno con el patronato de la Generalitat de Catalunya y fue promocionada desde publicaciones como Mirador y L'opinió como el primer gran film de la patria catalana. Sin embargo, la representación de Cataluña que ofrecía el film (también desaparecido) fue interpretada asimismo como parte de un imaginario nacional español, no alternativo a este ${ }^{32}$.

Los filmes de localización y temática regional no fueron solo resultado de proyectos cinematográficos impulsados por iniciativas locales, como podría pensarse, sino que ocupan un importante lugar en el cine producido por las principales productoras y distribuido por todo el territorio español. Es el caso de las principales productoras españolas, antes mencionadas, Filmófono y Cifesa. Se trata, además, de películas que contaron con un gran éxito de público, hasta el punto de desbancar a los filmes de Hollywood en la taquilla. Cabe destacar también la presencia de, si no todas, buena parte de las regiones en la cinematografía española realizada durante los años de la República. Así, puede verse temática regional gallega en Alalá (A. Trotz, 1933) o La casa de Troya (J. Vila Vilamalá, 1936), catalana en El café de la marina (D. Pruna, 1933), charra en El cura de la aldea (F. Camacho, 1935), aragonesa en Miguelón o el último contrabandista (A. Aznar, H. Behrendt, 1933) o andaluza en María de la $O$ (F. Elías, 1936), por citar algunos filmes destacados del periodo. Por otra parte, cabría añadir la explotación del costumbrismo madrileñista (en filmes como La verbena de la Paloma, Doña Francisquita o Don Quintín el amargao) que dentro de la narración nacional sobre España funciona de forma equivalente a un imaginario regional. En algunos casos puede resultar sorprendente que determinadas regiones no generaran una elaboración cinematográfica más destacada. Este es el caso valenciano, que contaba con todo un imaginario simbólico regional codificado que, además, en los años veinte había sido representado cinematográficamente en films de éxito como Rosa de Levante, Nit d'Albaes o Les barraques. Todavía resulta más chocante que no realizara ningún film sobre ello Cifesa, que convirtió algunos símbolos de la identidad valenciana, como el himno regional o el Micalet, en los emblemas de la marca.

En cualquier caso, no hay que perder de vista que durante los primeros años de la década la producción cinematográfica en España estuvo práctica-

32 En este sentido, algunas revistas barcelonesas situaban a España como el marco al que la película hacía referencia (ver, por ejemplo, "Se prepara la presentación de El café de la marina”, El cine XXIV/5, 1-2-34) y lo mismo hacía su propio director con declaraciones sobre el film y sus intérpretes como: "Mi criterio es que los intérpretes de una película española, de amplitud nacional por su ambiente, igual que de sabor puramente regional, deben tener un tipo genuinamente español. [...] de lo que se trata es de hacer películas, buenas, medianas o malas, pero con un estilo español”, en SANTOS, 1933. 
mente paralizada (por las dificultades que tuvo la industria cinematográfica para adaptarse a la nueva tecnología del sonoro), y solo a partir de la temporada de 1933/34 se alcanzó un nivel de producción que se mantuvo de forma creciente hasta el brusco corte que supuso el inicio de la guerra civil. Así, cuando hablamos de la producción cinematográfica de los años republicanos nos referimos a un volumen considerable pero limitado de películas realizadas casi todas ellas durante apenas tres temporadas cinematográficas.

\section{ANDALUCÍA Y ARAGÓN: DOS REgIONES, UNA NACIÓN}

En términos cuantitativos, Andalucía fue la región que más apareció en la pantalla y su construcción cinematográfica fue posiblemente la que suscitó reacciones más ambivalentes. Por una parte, el folclore andaluz aparecía como la máxima expresión de la «españolada» extranjera de origen francés y explotada por Hollywood desde hacía años, interpretada como una deformación caricaturesca del «verdadero» carácter español. No obstante, se trataba de un elemento firmemente asociado al imaginario español, al que los cineastas no querían renunciar y que formaba parte de la cultura de masas, con lo que el éxito de público parecía garantizado, como habían demostrado algunos títulos del cine mudo. Asimismo, con el cine sonoro nacía el género musical, con el que el imaginario andaluz quedó fuertemente asociado. Compañías como Filmófono y Cifesa buscaron en la región andaluza el escenario e inspiración para algunos de sus filmes más conocidos. El cine entraba así en una compleja dialéctica en torno a lo andaluz que se venía desarrollando ya en la cultura española en las décadas anteriores. Las canciones y los bailes andaluces habían inundado teatros y cafés desde finales del XIX, favoreciendo así su rápida aceptación masiva como parte de la cultura nacional popular. Mientras el andalucismo era explotado con éxito en piezas teatrales populares como las de los hermanos Álvarez Quintero, la aspiración a la destilación de las «esencias puras» andaluzas de los «falsos tópicos» se convirtió en una prioridad del modernismo y la vanguardia, desde J. R. Jiménez y A. Machado a Falla y Lorca, pero también apareció en intelectuales como Ortega y Gasset o Eugenio Noel, aunque fuera con tintes irónicos y distanciados ${ }^{33}$. De este modo, a lo largo de las primeras décadas del siglo el imaginario andaluz fue constantemente modelado y remodelado como materia estética, proceso en el que el cinematógrafo también participó ${ }^{34}$.

33 VVAA, 2003. Sobre la compleja relación entre flamenco, cultura popular, nacionalismo, intelectualidad, v. algunos trabajos recogidos en STEINGRESS y BALTANÁS, 1998.

34 BALTANÁS, 2003. 
La voluntad de enlazar con el afán depurador del folclore andaluz se hace patente en un film como La hija de Juan Simón (J. L. Sáenz de Heredia, 1935) ya desde los eslóganes que acompañaron al cartel del film, en los que se podía leer:

NO es la españolada hecha en España, la pandereta, la castañuela y el toreador. ES el espíritu del más recio folklore nacional con el grito de una copla española. NO ES lo colorista, lo pintoresco, la mantilla y el clavel. ES la fatalidad inmensa y honda de una raza, llevada a la pantalla. NO es el andalucismo de sainete, el chiste fácil y los tipos chabacanos. ES un tema de auténtica raíz popular, tratado en el más alto tono del más puro arte ${ }^{35}$.

El film se presenta así como representación de la autenticidad de la raza y el folclore andaluz («el más recio folklore nacional») en su esencia popular, en contraste con las imágenes tópicas sobre Andalucía. Así, la publicidad asociaba la película a la obra de Falla y Lorca en su resolución por la elevación de lo popular a la categoría de arte:

NO es una película de lo que hasta ahora se ha llamado fácilmente «ambiente popular». ES lo que la música de Falla o los romances gitanos de García Lorca: la superación de la raíz popular del arte. NO ES solamente una película netamente española. ES una gran obra de arte sobre un formidable tema español ${ }^{36}$.

En el mismo sentido, el estreno del film en Barcelona se acompañó de un concierto con piezas de Albéniz, Granados y Falla. El vínculo con el neopopularismo andaluz de la generación del 27 se establece también por la persona que estuvo detrás de la realización del film: Luis Buñuel. Si bien no quiso que su nombre apareciera en los créditos, Buñuel fue el productor ejecutivo de Filmófono y controlaba todos los aspectos de la película, económicos, técnicos, creativos y de realización ${ }^{37}$; en este caso concreto, primero Nemesio Sobrevila y luego Sáenz de Heredia dirigieron el rodaje según sus indicaciones exactas. Como se ha apuntado en un reciente trabajo, la labor del director aragonés en Filmófono no puede ser analizada como incompatible con su compromiso político comunista del momento, sino que más bien cabe situarla en el interés por consolidar un cine de orientación popular en un momento en que una filmografía de orientación política directa habría tenido casi nulas oportunidades para ser distribuida en la cartelera comercial $^{38}$.

\footnotetext{
35 Popular film, n. ${ }^{\circ}$ extraordinario (30-1-36).

36 Cinegramas, II/66 (15-12-35).

37 GUBERN y HAMMOND, 2009.

38 GUBERN y HAMMOND, 2009: 223 y ss.
} 
La hija de Juan Simón es un melodrama inspirado en una canción popular muy conocida que había dado lugar a una obra teatral (escrita por Sobrevila y José María Granada en 1930 y dedicada, muy significativamente, a Manuel Machado). La película contaba la desafortunada historia de amor entre Carmen, la hija del enterrador de un pueblo andaluz, y el cantaor Ángel, en un argumento no muy original en el que encontramos un hijo ilegítimo y abandonado, fruto del amor prohibido de la pareja, el encarcelamiento injusto de Ángel por un crimen cometido en realidad por una bailarina de flamenco y su posterior carrera de éxito como cantante, en paralelo a la degradación de Carmen, forzada a trabajar en un cabaret de mala reputación en Madrid, de donde es rescatada por Ángel y redimida por su amor.

En general, la crítica del momento, si bien apuntó en muchas ocasiones la endeblez de una trama folletinesca plagada de tópicos, señaló como un aliciente que el film suponía una «valorización cinematográfica del folclore español» ${ }^{39}$. El film destaca, en primer término, por la reiterada presencia de elementos del folclore andaluz, particularmente la canción y el baile. Se eligió al cantaor Angelillo, que ya había participado en dos filmes (El sabor de la gloria y El negro que tenía el alma blanca) como protagonista principal para aprovechar su celebridad como cantante de temática andaluza; de hecho, aunque era de origen madrileño, era conocido como «el ruiseñor de Andalucía» o «el Fleta del arte lírico andaluz». Para la película se incorporó material musical ya de éxito en el mercado (como Soy un pobre presidiario) junto a canciones compuestas directamente para la película por Daniel Montorio. En este sentido, ejemplifica la importante presencia en el cine de la República de la canción popular española ${ }^{40}$, que la radio y el gramófono habían contribuido a popularizar. Cine y música se mezclaba y retroalimentaban así en la elaboración mítica del relato sobre un cantaor andaluz de origen humilde que consigue el éxito y la gloria gracias a su aptitud natural para la canción. Si en un principio se asocia el flamenco y el cante con la vida juerguista y bohemia de las tabernas, la trayectoria de Ángel como cantante le proporciona finalmente respetabilidad y ascenso social, además de fama internacional ${ }^{41}$.

El ascenso de Ángel se produce en paralelo con la narración de la caída de Carmela. El «deshonor» de una mujer por quedarse embarazada fuera del matrimonio fue una línea argumental recurrente en el cine del momento, y en La hija de Juan Simón, como en otros filmes, lleva a la protagonista al borde

39 Crítica en Films selectos 274 (18-1-36).

40 En algunos casos directamente en el título, como El relicario (R. de Baños, 1933), El gato montés (Rosario Pi, 1935) o María de la O (F. Elías, 1936).

41 En este sentido, nos encontramos con narrativa sobre el folclore como trampolín para el ascenso social, una narrativa que estuvo muy presente en el cine español en años posteriores según ha estudiado WOODS, 2004. 
de la prostitución. Aunque el argumento suaviza en su desenlace la tragedia del tema original (que suponía la muerte de la protagonista), La hija de Juan Simón es un film de estética sombría en general. De hecho, la película se inicia en un cementerio, una secuencia inicial tétrica que parece servir como presagio del destino de la protagonista femenina, según cantaba la canción, y marca una pauta estética que se mantendrá a lo largo del film. En numerosas escenas, la fotografía se llena de claroscuros y sombras. Incluso algún crítico de la época llegó a comentar que el film tenía cierto aire expresionista, y algún analista ha establecido un vínculo de esa «negrura» estética con la plástica de José Gutiérrez Solana ${ }^{42}$. Valga como ejemplo la secuencia del baile de la gitana Soledad, rodada con múltiples claroscuros y sombras en una taberna en la que tras la actuación de la bailaora se inicia una riña y la gitana apuñala a un hombre, asesinato por el que será encarcelado Angelillo. Pese a la breve aparición del personaje de Soledad en la película (en el que era el primer papel cinematográfico de la bailaora Carmen Amaya), juega un papel simbólico clave en su narración sobre Andalucía. En primer lugar, personifica con su baile, lleno de pasión, a la esencia del folclore andaluz. En María de la O (F. Elías, 1936), de nuevo Carmen Amaya, ahora protagonista absoluta, aparece como representación del «verdadero» flamenco, ya que la película contrasta su baile con las sevillanas bailadas de forma fría y casi rutinaria por otras gitanas para los turistas frente al Palacio de la Alhambra. En segundo término, Soledad, cuya actitud seductora causa la muerte de un hombre y el encarcelamiento de otro, encarna a la mujer andaluza con un componente de fatalidad asociado.

La oscuridad y el ambiente sombrío en La hija de Juan Simón solo desaparece en las secuencias en exteriores de un soleado campo andaluz, especialmente al final cuando los protagonistas pasean felices a caballo entre los olivos al cortijo de Ángel, vestidos él con traje cordobés, y ella con vestido de volantes, a diferencia de la vestimenta urbana moderna que han llevado anteriormente.

Si la Andalucía de La hija de Juan Simón es en buena medida sombría y trágica, la luminosidad preside por completo la representación andaluza de $M o$ rena clara, la película más taquillera del cine español republicano. Esta comedia romántica basada en una obra teatral de Quintero y Guillén tiene como protagonistas a Trini, una gitana «clara» que vive de pequeños robos junto a su hermano Regalito, y Enrique, un fiscal payo muy serio de escrupulosa rectitud. El film está lleno de luz, aunque buena parte de él transcurre en interiores, y en su representación del espacio andaluz se trasluce un afán de elegancia y belleza plástica. Esta voluntad de estilización fue reconocida por algún comentarista de la época, que indicaba que en Morena clara se presentaba Andalucía como «un

42 GUBERN y HAMMOND, 2009. 
espejo típico y familiar, pero terso, limpio y claro [...] Bonita película, acuarela preciosa o alicatado feliz, cuyo símbolo podría ser el afiligranado encaje de una cancela andaluza» ${ }^{43}$. La fluidez de la puesta en escena, especialmente en las secuencias en que se aparta de la obra teatral, como la inicial del robo de los jamones, y la agilidad de sus diálogos dan al film una gran vivacidad.

Nos encontramos de nuevo con la presencia de canciones populares, con zambras, bulerías o soleares, que esta vez tienen como centro a una intérprete femenina, Imperio Argentina. También aparece el baile en la celebración de las Cruces de Mayo en casa del fiscal, una secuencia que destaca por la calidad y modernidad de su planteamiento cinematográfico, ya que el cuerpo de baile y sus modulaciones son seguidos por la cámara a través del decorado de arcos y cancelas del patio andaluz en una planificación que recuerda a los números musicales que en esos años realizaba Busby Berkley en Hollywood. El patio, espacio simbólico del imaginario andaluz, acoge su folclore retratado con un novedoso enfoque fílmico. Trini y Regalito, que se cuelan en la fiesta, toman el relevo inmediatamente cantando y escenificando Échale guindas al pavo, marcando el contraste entre la alta sociedad sevillana y los gitanos como representación popular.

La película sitúa la representación del pueblo andaluz en los personajes de Trini y Regalito, y en su carácter gitano. Los gitanos son caracterizados por su marginalidad, viven en cuevas fuera de Sevilla y son perseguidos (de modo cómico) por la Guardia Civil. Su pobreza, y la poca predisposición para el trabajo en el caso de Regalito, les lleva a robar, pero no son ladrones vulgares, sino que se sirven de su ingenio (venden a un tabernero sus propios jamones) de tal forma que ni siquiera se les puede condenar en el juicio. Los diálogos de los hermanos están plagados de agudezas, utilizadas como una muestra de una espontaneidad intrínseca al carácter andaluz. Este estereotipo del gitano alegre e ingenioso se exagera especialmente en el personaje de Regalito, que a pesar de su carácter secundario destaca en buena medida por la labor del actor que lo interpreta, Miguel Ligero.

El carácter íntrinsecamente andaluz de los gitanos está reforzado por el contraste con Enrique, de exagerada seriedad y siempre seguidor de las normas. No tiene acento andaluz y, aunque no queda muy claro de dónde es, se apunta que la familia vivió muchos años en Palencia. Su carácter serio se presenta como lo opuesto a la «gracia» andaluza, lo que hace que Enrique casi no parezca español, como le señala Trini: «Mira, les hago gracia. Esto no lo has conseguido tú nunca. Porque yo soy gitana "cruzá», morena clara, y tú eres holandés». Al contrario que su hermano Rafael, aficionado al cante y a los ambientes flamencos, Enrique deja patente en la primera parte de la película que no le gustan las cosas andaluzas como los bailes y menos aún los gitanos.

43 Crítica de Guzmán, Antonio, Cinegramas, 84 (19-4-36). 
Contra estos expone su discurso acusatorio como fiscal en el proceso por el robo (un discurso del que la cámara se distancia, pues las tomas del fiscal son todas desde lejos, en contraste con los insertos en primer plano de Trini):

A mí no me hace ninguna gracia la gracia aparente de los gitanos. Porque estoy convencido de que su agudeza, su zalamería, su ingenuidad y talante no son más que un tapiz de flores que oculta la intención dañina de unos enemigos perpetuos de la sociedad. Por regla general nacen, viven y mueren al margen de la gente.

Conociendo estos prejuicios, Trini intenta «desgitanizarse» para conquistarle cambiándose su habitual traje de volantes (ante las burlas de Regalito, que considera que va «vestía de dependienta») pero vuelve a ponérselo enseguida y apuesta por su belleza y gracia para seducir al fiscal.

Así, se establece un esquema de comedia romántica entre dos protagonistas de carácter opuesto que pasan de la animadversión al amor. La tensión entre ambos se traduce en intercambios dialécticos punzantes y en el intento de seducción por parte de Trini y los intentos de Enrique por resistirse. El patio andaluz, con los elementos de la fuente, los arcos lobulados y las rejas, es el escenario fundamental en el que se desarrolla el tira y afloja entre los dos protagonistas. Finalmente, Trini desmonta las prevenciones de Enrique al ayudar a su familia y demostrarle que una gitana puede llevar una vida honrada sin renunciar a su carácter sevillano y calé44. De hecho, es de ese «natural» encanto andaluz del que el fiscal cae enamorado. El triunfo de Trini es la victoria de Andalucía, solo allí, en esa Andalucía mítica que tiene un «duende» especial, podía rendirse el carácter serio y estirado de Enrique, y de este modo se interpretó en su momento:

No se trata de una Andalucía de pandereta, sino de una Andalucía estilizada. Una Andalucía que podría definirse a la manera orteguiana —en lo que tiene Andalucía de helénica. [...] Es allí donde únicamente puede flaquear el temperamento férreo, hermético, de un fiscal, que le hace tomar una borrachera de manzanilla, darse un chapuzón en la piscina de un patio o caer de lleno en el abismo de unos ojos negros ${ }^{45}$.

Buena parte de la crítica apreció así la película como « una certera visión de Andalucía, de una Andalucía genuina, sin deformar por los prismas de falsos pintoresquismos con que estamos acostumbrados a que nos las presen-

44 De hecho, recurre humorísticamente al propio estereotipo gitano fingiendo un conjuro en el que recurre «a la ciencia de Egipto» y recitando un galimatías antes de conseguir solventar los problemas económicos de Rafael y los matrimoniales de don Elías.

45 Crítica en La Voz, 16-4-36. 
ten en otros films ${ }^{46}$. Se valoraba que pese a (o tal vez gracias a) la ausencia de algunos referentes simbólicos asociados a Andalucía, la película representaba el alma andaluza sin tópicos: «es un film andaluz, y no hay en él saetas; es una película gitana y no aparecen toreros. Y, sin embargo, es Andalucía, jugosa y palpitante, la que vive en el lienzo sonoro, y es el alma gitana la que vibra en la acción cinematográfica» ${ }^{47}$. Florián Rey había conseguido por ello «un film de raza, donde se nos entrega viva y palpitante el alma apasionada y el garbo exquisito del folklore andaluz» ${ }^{48}$.

Algunos críticos agradecían también la ausencia de un discurso sobre la honra femenina y un registro cómico que buscaba alejarse de la tosquedad y vulgaridad que en ocasiones acompañaba a la representación de los estereotipos populares. Un argumento «que no nos denigrará ante los públicos extranjeros; tema español, pero sin toreros ni cantaores, sin jóvenes seducidas ni hijos abandonados, y, sobre todo, sin pueblo cerril» ${ }^{49}$. De esta forma, el populismo de Morena clara se interpretaba como una representación positiva, auténtica, del pueblo andaluz, y por extensión, español.

Andalucía podría parecer un caso evidente de la automática identificación de un discurso sobre lo regional al imaginario nacional. Sin embargo, vamos a plantear el ejemplo de otra región, Aragón, cuya construcción cinematográfica funciona en el mismo sentido.

La región aragonesa tiene una presencia destacada en la cinematografía de la II República, no tanto por el número de filmes realizados sobre ella como por la resonancia y notoriedad que alcanzaron dos de estos: La Dolorosa (J. Gremillon, 1934) y Nobleza baturra (F. Rey, 1935). El primero se basaba en la zarzuela de J. J. Lorente con música del maestro Serrano, que se había estrenado en 1930 con enorme éxito de público. El film pretendía aprovechar el tirón popular de la zarzuela y la popularidad de las obras del maestro Serrano; de hecho, alguno de los anuncios publicitarios insertos en prensa antes de su estreno no incluía imágenes de los actores, sino de Serrano ${ }^{50}$.

$\mathrm{El}$ argumento de la película sigue fielmente a la zarzuela, si bien en su elaboración formal el director procuró evitar una puesta en escena «teatral» y la adaptación cinematográfica aportaba algunas innovaciones respecto a la imaginación de la región aragonesa. Por ejemplo, la música fue adaptada para la pantalla con una instrumentación más moderna. Asimismo, en la película hay abundantes planos aéreos y diversas tomas de Albarracín y otros parajes cer-

46 Barbolla, Luis, "Una nueva creación de Imperio Argentina en Morena clara", Celuloide madrileño, 4 (1-4-36).

47 Crítica en La Libertad, 14-4-36.

48 Crítica en Informaciones, 14-4-36.

49 Crítica de Barbero, Antonio, ABC 14-4-36.

$50 \mathrm{~V}$. el anuncio del estreno en el cine Callao de Madrid en $A B C, 20-12-34$. 
canos. El medio fílmico permite así una elaboración audiovisual del paisaje aragonés imposible de plasmar en la representación zarzuelera.

El inicio del film sintetiza que Aragón es el espacio fílmico y dispositivo narrativo fundamental: los títulos de crédito se superponen encima de un dibujo en el que se combinan la basílica del Pilar y una pareja vestida con el traje regional bailando jotas con unas notas musicales mientras comienza a sonar la melodía principal de La Dolorosa. Se recurría así en el inicio del film a dos elementos, por una parte, la aragonesidad del film, cifrada en El Pilar (que no aparece en la película) y en el traje y baile regional; por otra, se apelaba a un elemento de reconocibilidad para el público con una música que se había hecho enormemente popular tras el éxito de la zarzuela.

El Aragón de La Dolorosa se proyecta en un espacio narrativo escindido en tres ámbitos, urbano, monacal y rural, que marca una delimitación entre clase media urbana, monjes y campesinos solo traspasada por la pareja protagonista, y no completamente ${ }^{51}$. En el espacio urbano es donde se conocen los protagonistas, Rafael y Dolores, y donde esta es seducida por un vividor. Desesperado por su amor no correspondido, Rafael ingresa como novicio en un convento ubicado en el campo aragonés y cercano a un pequeño pueblo en el que viven Perico y Nicasia, una pareja de campesinos que espera anhelante el momento de casarse. Dolores, abandonada con un hijo ilegítimo y con el pesar de haber causado la muerte a su madre por su deshonra, vaga solitaria por los campos hasta que es auxiliada y acogida por la familia de Perico. Tras reencontrarse con su antiguo amor y comprender que sigue enamorado de ella, Rafael abandona el convento y Dolores decide acompañarle. Una escisión reforzada por la música que acompaña a los personajes identificados con cada uno de estos tres espacios: números líricos casi operísticos para los protagonistas, coro religioso para los frailes y folclore aragonés para los campesinos del pueblo.

En esos escenarios de clase media urbana es, por tanto, donde Dolores se deja seducir, donde muere su madre, fulminada (simbólica y literalmente) por la deshonra, y donde Natalio le abandona. El «irresponsable» comportamiento de Dolores motiva que ambos abandonen el espacio urbano y su vida de clase media. Rafael busca refugio de su desamor ingresando como novicio en el convento, espacio de paz pero donde no encuentra sosiego espiritual. El personaje de Dolores experimenta una transformación mayor: la joven alegre y frívola se convierte en una mujer abrumada por el dolor y la culpa, que vaga solitaria por los campos sin rumbo. Finalmente, en el mundo rural se produce el perdón del pecado de Dolores (cometido en la ciudad) y el final feliz para ella y Rafael, con lo que se reivindica simbólicamente como el espacio arago-

51 La escisión del espacio en La Dolorosa fue puesta de relieve por Imanol Zumalde en su análisis del film desarrollado en ZUMALDE, 1997: 92-94. 
nés puro y esencial. Un universo campesino que se explora en secuencias colectivas, como la breve escena de trilla que da paso a la fiesta nocturna en la que los aldeanos bailan en corro alrededor de una hoguera. Ese ambiente festivo popular es rápidamente contrastado, gracias al montaje alterno, con la severidad del convento donde Rafael lamenta sus penas amorosas.

El film plantea un melodrama y todos los dispositivos narrativos se dirigen a reforzar el componente melodramático. No obstante, se introducen elementos cómicos que rebajan el dramatismo general de la película pero que cumplen asimismo una función narrativa, de caracterización del espacio rural como un ámbito feliz. La comicidad proviene básicamente de la interacción entre dos parejas: Perico y Nicasia por una parte y sus padres, el tío José y el tío Bienvenido. Son estos campesinos humildes los que representan la encarnación del pueblo aragonés, caracterizados como rústicos y un tanto brutos, bondadosos y felices, siguiendo así el estereotipo del baturro, si bien sin exagerarlo. Los personajes campesinos emplean un lenguaje con abundantes locuciones, acento aragonés y hablan frecuentemente a gritos.

Tanto Rafael como Dolores se relacionan con el mundo campesino a través de los personajes secundarios, pero sin llegar a participar completamente de él. La pareja protagonista no forma parte de ese mundo campesino, en todo momento se marca la distancia; por ejemplo, con el tratamiento formal de «usted» $\mathrm{y}$ «señora» que utilizan para dirigirse a ellos los habitantes del pueblo. Tampoco visten el traje regional, participan en las fiestas populares ni utilizan la entonación y diminutivos propios del dialecto aragonés que caracteriza el habla de Perico, Nicasia y sus padres. La distinción queda marcada también en el contraste entre las respectivas historias de amor entre los protagonistas y la pareja de baturros, la primera marcada por la separación y el drama y la segunda por la comicidad y el contacto. La distinción queda marcada también en el contraste entre las respectivas escenas musicales de amor de los protagonistas y la pareja de baturros. En el dúo de los primeros, Rafael y Dolores cantan el tema por separado, distanciados física y emocionalmente. Para unir visualmente a la pareja se recurre a la sobreimpresión de los personajes sobre paisajes aragoneses o escenas anteriores que recuerdan la desdichada trayectoria de Dolores. La secuencia adquiere así un carácter casi onírico, lejos de la terrenidad de Perico y Nicasia, seguidos con cercanía por la cámara mientras cantan su amor de forma desenfadada y un tanto cómica, abrazándose y bailando espontáneamente unos pasos de jota.

El mismo espíritu alegre preside la secuencia colectiva de la trilla y las escenas dedicadas a las fiestas populares, en las que todo el pueblo va vestido con el traje regional y participa en actos como la procesión de cabezudos, cantos de rondallas y bailes de jotas. Es en paralelo con estas celebraciones que se produce el final encuentro feliz entre Dolores y un Rafael vestido ahora como los campe- 
sinos (en contraste con la ropa urbana que llevaba al principio del film y el hábito de monje que vestía posteriormente). Ellos no llegan a participar en los actos festivos, pero mediante el montaje se asocia su encuentro con los cantos y bailes regionales: la comunidad popular aragonesa ha redimido a la pareja.

La película obtuvo muy buena acogida crítica, a pesar de que al conocerse el proyecto habían surgido no pocas suspicacias por el hecho de que su director no fuera español ${ }^{52}$. Aunque Jean Gremillon era un realizador de reconocida solvencia, se entendía que un extranjero no sería capaz de comprender el temperamento español y darle expresión cinematográfica: «Ardua y difícil empresa por tratarse de un director cuya mentalidad había de rehuir obras de este tipo, y por ende de un francés, que había de encontrar en ella cosas que, por ser muy españolas, habían de escaparse de sus manos» ${ }^{53}$. Pese a estas prevenciones, el resultado convenció a los comentaristas en prensa, que interpretaron que el film había captado las «características raciales» de la obra teatral, sus «valores espirituales, las expresiones psicológicas, y lo que la obra tiene de reciamente ibérico», y la había trasladado brillantemente a la pantalla: «A la obra de un poeta de la palabra se unió el esfuerzo de un verdadero poeta de la imagen, y el resultado fue esta versión, en la que todo se resuelve cinematográficamente» ${ }^{54}$. Asimismo, se destacaba «el acierto de haber tomado los exteriores con todo su sentido de paisaje típicamente español» ${ }^{55}$. Algún crítico incluso apuntó que el realizador francés, a quien «le atrae España, le atraen sus paisajes, su historia, sus costumbres y todo cuanto tenga ese sabor racial español», daba una lección a algunos directores españoles que «se marchan al Extranjero o realizan obras inspiradas por ese falso internacionalismo que tanto ha empleado Hollywood» ${ }^{56}$. De este modo, la película era sancionada como una conseguida expresión del alma aragonesa y, por tanto, de España: «En una palabra, La Dolorosa, sea o no aceptada por la masa, es un buen film, un film español, con imágenes española, sentimientos raciales, peculiarísimos ambientes y formas nuestras» ${ }^{57}$.

Con lemas como «El primer homenaje al alma aragonesa hecho con la música y el lenguaje de la tierra» se promocionó el film Nobleza baturra, que ya desde su título hace de la identidad maña su característica distintiva y se postula como

52 Por ejemplo, Barbero, Antonio, "Primeros planos”, ABC, 17-10-34.

53 Crítica en Films Selectos, 227 (23-2-35).

54 La Dolorosa, Popular film, 442 (7-2-35).

55 Crítica en Sparta. Revista técnica de la cinematografía, 10 (7-1-35).

56 Crítica de Del Amo, Antonio, Cinegramas, 16 (30-12-34). Nótese el despectivo uso de «internacionalismo» como opuesto al carácter nacional y racial que debía inspirar al cine español, una consideración muy extendida en la cultura cinematográfica española del momento y que en este caso es expuesta por un crítico, del Amo, simpatizante comunista y firma habitual en la publicación de orientación marxista Nuestro cinema.

57 Crítica de Martínez de Ribera, Lope F., Popular film, 443 (14-2-35). 
el fiel retrato de su esencia. Para dejar bien asentado su carácter aragonés y español, el estreno se hizo coincidir en toda España con las fiestas del Pilar y la Raza. En esta ocasión no se trataba de la adaptación de un texto teatral, sino del remake de uno de los mayores éxitos de taquilla del cine español en la década anterior. $\mathrm{Al}$ igual que La Dolorosa, la película fija en el ámbito rural las esencias populares que encarnan los valores aragoneses, pero en este caso no hay ninguna escisión, pues el universo campesino es el único espacio de representación y en él están incluidos todos los personajes. La vestimenta, el habla y los cantos y danzas regionales uniformizan a los lugareños como miembros de la comunidad aragonesa, no hay diferenciaciones en función de la clase social o el sacerdocio, pues el padre Juanico es tan baturro que hasta baila jotas.

El conflicto melodramático viene dado por el comportamiento deshonesto de Marcos, un propietario adinerado que, despechado por la indiferencia de Pilar, enamorada de un jornalero pobre, provoca unos rumores que ponen en entredicho la honra de la muchacha y que se extienden por la población en forma de copla. El que el villano del film sea un propietario rico mientras el héroe masculino es un modesto campesino apunta a un populismo concretado en los estratos más humildes. Sin embargo, la vindicación populista de la película no apela exclusivamente a las clases bajas, ya que las diferencias sociales no son motivo de conflictos: amos y peones trabajan, cantan y se divierten juntos. El problema fundamental de Marcos no es que sea rico, sino que carece de la cualidad que el film sitúa como atributo intrínseco al carácter aragonés: nobleza; es decir, el pueblo de Nobleza baturra no se define en términos socioeconómicos, sino morales. Los aspectos más toscos del estereotipo baturro se concentran en Perico, un personaje similar al de su homónimo en la película antes comentada, pero que en ésta cumple un papel cómico más acusado.

El mundo rural aragonés es retratado en el film con una fotografía muy cuidada que combina la cercanía y el cuidado detalle en la representación del trabajo y folclore, retratados con espíritu de alegría y celebración, con un realismo estilizado que busca la belleza en el tratamiento loatorio de la sociedad campesina. Las secuencias que retratan las labores campesinas y las fiestas populares (como la de la trilla inicial o la de la fiesta en casa del tío Eusebio) adquieren mayor importancia que en La Dolorosa por ocupar un espacio más dilatado en el metraje y por un tratamiento cinematográfico más rico. Especialmente destacado es el intento de engarzar el baile de las jotas con la sintaxis fílmica, cambiando de cámara y encuadre según evoluciona la melodía. En su estreno, la crítica valoró muy positivamente ese trabajo fílmico: «Las escenas de la danza son difícilmente superables. Que nosotros sepamos, nunca había sido tratada la jota, desde el punto de vista técnico, con tanta soltura»58.

58 Gracián, Antonio, “Nobleza baturra, un film español dirigido por Florián Rey e interpretado por Imperio Argentina”, La Vanguardia, (9-10-35). 
En las valoraciones en prensa del film, nos encontramos con opiniones que destacan el acierto del director en el retrato de los personajes y costumbres de Aragón:

Florián Rey, a fuer de buen baturro, ha llevado a la pantalla el argumento original de Dicenta (hijo) con todo acierto, pero adicionándole de su cosecha una serie de tipos y costumbres tan netamente aragoneses que de no ser de la tierra hubieran perdido mucho colorido y sabor. La trama es de recia raigambre: el tesón y la nobleza aragoneses frente a frente ${ }^{59}$.

El paisaje y el folclore de Nobleza baturra encarnaban con fidelidad la esencia aragonesa y por ello la película, lejos de pintoresquismos falsos, era una representación fidedigna de España:

Es una película neta y limpiamente española, sobria, alegre, sin chocarrerías, y emocionante sin sensiblerías ni efectismos. Muy española, no asoman a ella, sin embargo, los colorines de lo falsamente español. Sus fondos son los fondos, tan nuestros, de la campiña aragonesa. Y esa misma emoción, recta, noble y franca, del alma de Aragón es la que palpita a lo largo de las escenas de este film60.

De esta forma, Aragón funciona, y así se interpretaba en el momento, igual que Andalucía, como epítome de España.

\section{A MODO DE CONCLUSIÓN}

Las cuatro películas analizadas ejemplifican la importante presencia de las regiones en el cine español de los años treinta. Los films destacados no agotan, obviamente, todo el cine español producido durante los años de la II República, pero son algunos de sus títulos más célebres, tanto por su éxito de público como por su calidad cinematográfica. Lo cierto es que para estas fechas, no resulta fácil determinar el impacto social de un film, pues no contamos con estudios de recepción rigurosos y tampoco puede cuantificarse con exactitud el número de espectadores que vieron los filmes. No obstante, tenemos diversos indicadores a partir de los cuales puede plantearse con ciertas garantías la hipótesis del éxito de una película. Por una parte, contamos con algunos estudios locales que dan cuenta del éxito y la popularidad del cine español en general (y en particular de las películas señaladas) en estos años ${ }^{61}$. Por otra parte, pueden servir como datos indicativos las cifras totales recau-

59 Crítica en Heraldo de Madrid, (12-10-35).

60 “Una nueva creación del cinema español: Nobleza Baturra”, Cinegramas, II-47 (4-8-35).

61 Ver SBERT, 2001: 114. AMAR, 1997: 97-168. JURADO 1997: 161 y ss. QUIROGA, 1989. 
dadas, cuando las hay, en relación con el coste de producción de la película y el precio de las entradas ${ }^{62}$. En este sentido, por ejemplo, La hija de Juan Simón fue un gran éxito, pues su coste se amortizó solo con la venta de discos y en el primer trimestre de 1936 la película había recaudado ya 600.000 pesetas, que habían superado el millón al terminar el primer semestre. De La Dolorosa comentaba la revista Popular film que en sus primeros siete días en la cartelera en un cine de Barcelona había recaudado veinticinco mil pesetas ${ }^{63}$. En el caso de Morena clara, las cifras fueron todavía más espectaculares: su coste de más de medio millón de pesetas se amortizó solo con las ganancias obtenidas en el cine Rialto de Madrid. Otro indicador del éxito de un film nos lo da el tiempo de permanencia en cartel (teniendo en cuenta, por supuesto, el tamaño de la ciudad y otros elementos). Nobleza baturra, por ejemplo, estuvo de forma casi ininterrumpida en la cartelera de Madrid desde su estreno en octubre de 1934 hasta marzo del año siguiente, siendo reestrenada sucesivamente por diversos cines de la ciudad y estando, en algunas ocasiones, en más de un local de proyección a la vez ${ }^{64}$. Asimismo, estos estudios nos permiten saber que durante la guerra muchos filmes producidos durante la República siguieron proyectándose o se reestrenaron con éxito. El caso más llamativo es el de Morena clara, que estuvo más de un año en cartel desde su estreno en abril de 1936 manteniéndose en los cines de ambos bandos varios meses durante la guerra ${ }^{65}$. Ello nos permite plantear que buena parte del imaginario sobre lo nacional y lo popular elaborado en la primera mitad de los treinta continuó siendo una pieza fundamental durante los años de la guerra.

Las cuatro películas analizadas plantean diferentes relatos sobre una comunidad regional, entendida siempre como representación de España. En ellas se utilizan elementos como las marcas dialectales en el habla, la vestimenta regional, el baile o la música para elaborar la representación de Andalucía y Aragón, respectivamente. Asimismo, todos los filmes nos muestran la inextricable relación de la cinematografía española de la II República con otras manifestaciones de la cultura de masas, como el teatro lírico (Morena clara y La Dolorosa), la canción popular (La hija de Juan Simón, Morena clara) o el cine mudo (Nobleza baturra). También es claro el diálogo con la literatura costumbrista en la construcción de estereotipos regionales.

62 En los años de la República el precio medio de la entrada de cine era de 1 pta., si bien podía encontrarse una amplia oferta de entradas de diverso precio, que podía variar según la población, el local y el tipo de localidad entre los 25 cts. y las 5 ptas., v. DÍAZ PUERTAS, 2003: 30-34.

63 "Pantallas de Barcelona”, Popular film, 445 (28-2-35).

64 Datos extraídos de la consulta de las carteleras a través del diario $A B C$.

65 Por ejemplo, en Madrid el título que más tiempo permaneció en cartel durante los años de la contienda fue la última producción Filmófono, ¡Centinela, alerta! (J. Gremillon, 1936), hasta cuarenta semanas. Cfr. CABEZA, 2005. 
En el caso de los filmes sobre Andalucía, nos encontramos con dos tipos de discurso distintos, pero complementarios, sobre lo andaluz. La hija de Juan Simón presenta una Andalucía dramática; por el contrario, Morena clara crea un espacio andaluz alegre y luminoso. La diferencia entre ambas narraciones queda marcada en el contraste entre dos espacios para la acción como son, respectivamente, la taberna y el patio, así como entre los personajes de Soledad y Trini, ambas gitanas pero con un carácter simbólico diverso (fatalidad la primera, gracia la segunda). No obstante, a pesar de las claras diferencias entre ambos filmes, tanto Morena clara como La hija de Juan Simón sitúan el folclore andaluz en el centro del imaginario regional.

En los dos filmes analizados sobre Aragón, hay una filiación clara de lo regional con el mundo campesino. En La Dolorosa esa identificación se refuerza por el contraste con la pareja protagonista, que pertenece al mundo urbano, y con los monjes. Los campesinos son quienes visten el traje regional aragonés, hablan con acento y giros idiomáticos maños y cantan y bailan jotas. En Nobleza baturra simplemente no se contempla otro espacio que el rural, retratado con un realismo atildado que busca la belleza en el tratamiento loatorio de la sociedad campesina. En ambos filmes el espacio rural aragonés se presenta como un mundo armonioso donde la comunidad campesina trabaja y celebra sus fiestas con alegría. Las dos películas presentan escenas de la trilla (mucho más elaborada en el caso del film de Florián Rey) y de bailes populares, con destacadas secuencias de jotas en ambos casos.

A partir del análisis de las películas que se ha planteado se deriva que ambos imaginarios regionales (y todos los demás que aparecen en el cine de la II República) se construyeron e interpretaron como representación paradigmática de la nación y el pueblo español. Estos filmes marcan la pertenencia o no a ese pueblo nacional y las virtudes de sus componentes a través del empleo de estructuras narrativas de tipo melodramático y sentimental. En este sentido resulta especialmente significativo que en varias de estas películas, como hemos apuntado, la trasgresión (real o ficticia) de la castidad femenina sea el motivo dramático que genera la inestabilidad de la comunidad nacional ${ }^{66}$. En Nobleza baturra, el hecho de que la protagonista demuestre su honradez reafirma la autenticidad de los valores aragoneses que encarna. En La hija de Juan Simón y La Dolorosa la «desviación» sexual es perdonada, tras una purga simbólica (abandono, tragedia, prostitución) y se produce la reintegración final por el perdón masculino, en la primera con la vuelta al campo andaluz y en la segunda en paralelo a la fiesta popular aragonesa. El espacio regional

66 Sobre la importancia de las metáforas de género en la definición y representación político-cultural de las comunidades nacionales y el peso de la significación otorgada a la conducta sexual culturalmente apropiada de las mujeres como símbolo de la pureza nacional, v. YUVAL-DAVIES, 1997. ELEY, 2000. BANTI, 2005. 
queda, así, fijado simbólicamente como el espacio que encarna la pureza nacional. En Morena clara lo que está en tela de juicio no es el comportamiento sexual de Trini, aunque se deja clara su castidad ${ }^{67}$, sino su integridad frente al estereotipo de los gitanos como ladrones y estafadores. En este film, la codificación genérica no es la de un melodrama, sino de comedia romántica, estructura que permite contrastar lo gitano como encarnación de Andalucía a lo no andaluz, con la victoria de Andalucía y la unión de la gitana pobre con el fiscal payo.

Asimismo, en estos imaginarios ocupa un lugar clave la representación de lo popular, manifestada a través de los folclores regionales. La vestimenta, las marcas dialectales en el habla, las canciones y los bailes no son tratados como algo artificioso, sino como una forma viva y distintiva del mundo popular español. Igualmente, ello nos lleva a resituar la comprensión de lo popular dentro de lo regional. Puede resultar sorprendente que ese tipo de representaciones fuera la forma de entender lo que era la cultura popular, en el momento en que esta ya había entrado en transformación, especialmente en ámbitos urbanos. Sin embargo, conviene entender que estas películas que en la actualidad nos pueden parecer imágenes en exceso estereotipadas y folclorizadas de lo regional no deben ser vistas a través del filtro que supuso el franquismo y que se ha transmitido hasta el presente. Por el contrario, como muestra el examen llevado a cabo de los filmes y su recepción crítica, en los años treinta estas formas de representación cinematográfica de la región no eran vistos necesariamente como un elemento caduco, sino que podían ser interpretados como la representación «legítima» de aquello que debía ser definido como lo verdaderamente popular, lo auténticamente español. Posiblemente, no habría que considerar la presencia de los folclores regionales como un mero resto del pasado sino valorar su incorporación a la moderna cultura de masas, en lo que el cine pudo jugar un papel fundamental ${ }^{68}$. Cabe destacar que en estos filmes encontramos, precisamente, una reelaboración en términos cinematográficos de temas ya tratados, pero que adoptan nuevas formas. El planteamiento fílmico de escenas de baile en Nobleza baturra o Morena clara o las sobreimpresiones empleadas en La Dolorosa son técnicas de sintaxis y composición fílmica absolutamente modernas en ese momento que transforman y dan un nuevo sentido a elementos como el baile de jotas y sevillanas o los duetos musicales completamente alejado de referentes teatrales o zarzueleros.

67 Interrogada en el juicio por su estado civil, Trini responde: «Soltera y mocita porque yo soy mu exigente».

68 En este sentido, es de gran interés el estudio realizado por Florencia Garramuño sobre la conversión en los años veinte y treinta de dos géneros musicales considerados primitivos o tradicionales como el tango y la samba en músicas nacionales modernas en Argentina y Brasil, señalando al cinematógrafo como un elemento decisivo en este proceso. GARRAMUÑO, 2007. 
Películas como La hija de Juan Simón o Nobleza baturra fueron realizadas (por directores tan diversos como Luis Buñuel, Florián Rey o Jean Gremillon y para productoras de distinto signo como Filmófono y Cifesa), valoradas (si no de forma unánime, sí muy amplia) por la crítica y vistas por el público como representaciones reconocibles, al mismo tiempo, de un ámbito regional específico y de lo auténtico español en su totalidad. Por ello, el cine de los años treinta pudo funcionar como un mecanismo muy poderoso, tal vez solo comparable en términos de difusión con la zarzuela, de nacionalización de las masas en la medida que permitió la reproducción de una cultura nacional de forma masiva. La producción generalizada por parte de empresas y directores de muy diverso signo, y el consumo, también generalizado, entre espectadores de diferentes partes de España, de unas representaciones compartidas sobre la región y la nación otorga al cine español en este momento un papel decisivo en la elaboración del marco de la comunidad imaginada.

\section{Bibliografía}

Aurora y melancolía. Actas del XIII Congreso de la Asociación Española de Historiadores del Cine, Santiago de Compostela, Vía Láctea, 2011.

Anuario cinematográfico español. 1935, Madrid, Unión Polígráfica S.A., 1935.

Amar, Víctor M., El cine en Cádiz durante la Segunda República, Cádiz, Servicio de Publicaciones Universidad de Cádiz, 1997.

Altman, Rick, Film/Genre, Londres, BFI, 1999.

Anderson, Benedict, Comunidades imaginadas: reflexiones sobre el origen y la difusión del nacionalismo, México DF, FCE, 1993.

Archilés, Ferran y Martí, Manuel, "Un país tan extraño como cualquier otro: La construcción de la identidad nacional española contemporánea”, en $\mathrm{M}^{\mathrm{a}}$ Cruz Romeo e Ismael Saz (eds.), El siglo XX. Historiografía e historia, Valencia, UVEG, 2002; 245-278.

Archilés, Ferran, "Hacer región es hacer patria. La región en el imaginario de la nación española de la Restauración”, Ayer, 64/4 (Madrid, 2006): 121-147.

Archilés, Ferran y Martí, Manuel, "La construcció de la regió com a mecanisme nacionalitzador i la tesi de la dèbil nacionalització espanyola”, Afers, 48 (Valencia, 2004): 265-308.

Baltanás, Enrique, La materia de Andalucía. El ciclo andaluz en las letras de los siglos XIX y XX, Sevilla, Fundación José Manuel Lara, 2003.

Banti, Alberto, L'onore della nazione. Identità sessuali e violenza nel nazionalismo europeo dal XVIII secolo alla Grande Guerra, Torino, Einaudi, 2005.

Bhabha, Homi, "Introduction: narrating the nation"», en Homi Bhabha (ed.), Nation and Narration, Londres, Routledge, 1990; 1-7.

Berger, Stefan, Eriksonas, Linas y Mycock, Andrew (eds.), Narrating the nation. Representations in History, Media and the Arts, Nueva York, Berghahn Books, 2008. 
Berthier, Nancy "Crítica cinematográfica y nacionalidad”, en Jean Claude Seguin y Nancy Berthier (eds.), Cine, nación y nacionalidades en España, Madrid, Casa de Velázquez, 2007; 11-24.

Billig, Michael, Nacionalisme banal, Catarroja, Afers, 2006.

Cabeza, José, El descanso del guerrero. El cine en Madrid durante la guerra civil española, Madrid, Rialp, 2005.

Cánovas, Joaquín, "Folclore y tipismo en el cine mudo español: La controvertida imagen de España", en Image et hispanité, Lyon, Publication du GRIMH/GRIMIA, 1998; 279-284.

Calhoun, Craig, Nacionalisme, Catarroja, Afers, 2008.

Caparrós, José $\mathrm{M}^{\mathrm{a}}$, Arte y política en el cine de la República, Barcelona, Ediciones Siete y Medio, 1981.

Caparrós, José $\mathrm{M}^{\mathrm{a}}$, El cine republicano español, 1931-1939, Barcelona, Dopesa, 1977.

Cubitt, Geoffrey, “Introduction”, en Geoffrey Cubitt (ed.), Imagining Nations, Manchester, Manchester University Press, 1998.

De Baecque, Antoine, La cinéphilie. Invention d'un regard, histoire d'une culture, 1944-1968, París, Fayard, 2003.

Del Rey, Antonia (ed.), "Celuloide hecho folleto turístico en el primer cine español”, en Antonia Del Rey, Cine, imaginario y turismo. Estrategias de seducción, Valencia, Tirant lo Blanch, 2007; 67-100.

Díaz Puertas, Emeterio, Historia social del cine en España, Madrid, Fundamentos, 2003; 30-34.

Edensor, Tim, National Identity. Popular Culture and Everyday Life, Oxford-Nueva York, Berg, 2002.

Eley, Geoff, "Culture, nation and gender", en Ida Blom, Karen Hagemann y Catherine Hall (eds.), Gendered Nations. Nationalisms and Gender Order in the Long Nineteenth Century, Oxford-Nueva York, Berg, 2000; 27-40.

Eley, Geoff y Suny, Ronald G., "Introduction: from the moment of social history to the work of cultural representation”, en Geoff Eley y Ronald G. Suny (eds.), Becoming National: A Reader, Oxford-Nueva York, Oxford University Press, 1996; 3-37.

Fanés, Félix, El cas Cifesa: vint anys de cinema espanyol (1932-1951), Valencia, Filmoteca Valenciana, 1989.

Fernández Colorado, Luis y Cerdán, Josetxo, Ricardo Urgoiti. Los trabajos y los días, Madrid, Filmoteca Española, 2007.

Fox, Inman, La invención de España, Madrid, Cátedra, 1997.

Fusi, Juan Pablo, España. La evolución de la identidad nacional, Madrid, Temas de Hoy, 2000.

Garramuño, Florencia, Modernidades primitivas. Tango, samba y nación, Buenos Aires, Tierra firme, 2007. 
García Carrión, Marta, “Escribir sobre cine para hablar de España: cultura cinematográfica y nacionalismo español en los años veinte y treinta”, en Ismael Saz y Ferran Archilés (eds.), Estudios sobre nación y nacionalismo en la España contemporánea, Zaragoza, Publicaciones Universitarias de Zaragoza, 2011; 169202.

García Carrión, Marta, Sin cinematografía no hay nación. Drama e identidad nacional en la obra de Florián Rey, Zaragoza, Institución Fernando el Católico, 2007.

Gauthier, Christophe, "Le cinéma des nations: invention des écoles nationales et patriotisme cinématographique (années 1910 - années 1930)”, Revue d'histoire moderne et contemporaine, 51/4, (París, 2004): 58-77.

Gubern, Román, “El cine sonoro (1930-1939)”, en Historia del cine español, Madrid, Cátedra, 1995.

Gubern, Román, El cine sonoro en la II República, 1929-1936, Barcelona, Lumen, 1977.

Gubern, Román y Hammond, Paul, Los años rojos de Luis Buñuel, Madrid, Cátedra, 2009.

Hayward, Susan, French National Cinema, Nueva York, Routledge, 2005.

Hake, Sabine, German National Cinema, Londres-Nueva York, Routledge, 2002.

Heinink, Juan B. y Vallejo, Alfonso, Catálogo del cine español, F3. Films de ficción 1931-1940, Madrid, Cátedra-Filmoteca Española, 2009.

Higson, Andrew, Waving the Flag. Constructing a National Cinema in Britain, Oxford, Clarendon, 1995.

Hjort, Mette y Scott Mackenzie (eds.), Cinema and Nation, Londres-Nueva York, Routledge, 2000.

Holguin, Sandie, República de ciudadanos. Cultura e identidad nacional en la España republicana, Barcelona, Crítica, 2002.

Jurado, Rafael, Los inicios del cinematógrafo en Córdoba, Córdoba, Filmoteca de Andalucía, 1997.

Mainer, José Carlos, “La invención estética de las periferias”, en Centro y periferia en la modernización de la pintura española, Barcelona, Àmbit, 1993; 27-33.

Moreno, Javier, "El fin de la melancolía”, en Javier Moreno (ed.), Construir España. Nacionalismo español y procesos de nacionalización, Madrid, Centro de Estudios Políticos y Constitucionales, 2007; 13-24.

Nogueira, Xosé, A evolución da imaxe cinematográfica en Galicia desde la II República ata os nosos días, Tesis doctoral inédita, Universidad de Santiago de Compostela, 2004.

Núñez Seixas, Xosé Manuel, “The region as the essence of the fatherland: regional variants of Spanish nationalism”, European History Quaterly, $31 / 4$ (Londres, 2001): 483-518.

Núñez Seixas, Xosé Manuel, ¡Fuera el invasor! Nacionalismos y movilización bélica durante la guerra civil española (1936-1939), Madrid, Marcial Pons, 2006.

Núñez Seixas, Xosé Manuel, "Hijacked Heimats: national appropriations of local and regional identities in Germany and Spain, 1930-1945”, en: European Review of History: Revue Europeenne d'Histoire 15/3 (Budapest, 2008): 295-316. 
Özkirimli, Umut, Contemporary Debates of Nationalism. A Critical Engagement, Nueva York, Palgrave, 2005.

Özkirimli, Umut, Theories of Nationalism. A Critical Introduction, Nueva York, Palgrave, 2010.

Quiroga, Alexandre, Haciendo españoles. La nacionalización de las masas durante la dictadura de Primo de Rivera (1923-1930), Madrid, Centro de Estudios Políticos y Constitucionales, 2008.

Quiroga, Luis M., "Una productora cinematográfica en la Galicia republicana: la Folk", en Actas del VI Congreso de la A.E.H.C., Madrid, Academia de las Artes y las Ciencias Cinematográficas de España, 1998; 111-120.

Saz, Ismael, España contra España. Los nacionalismos franquistas, Madrid, Marcial Pons, 2003.

Sbert, Cristòfol-Miquel, El cinema a les Balears des de 1896, Palma, Documenta Balear, 2001.

Schlesinger, Philip, “The sociological scope of National Cinema”, en Mette Hjort y Scott Mackenzie (eds.), Cinema and Nation, Londres-Nueva York, Routledge, 2000; $19-31$.

Seguin, Jean Claude, "El cine en la formación de la conciencia nacional", en Jean Claude Seguin y Nancy Berthier (eds.), Cine, nación y nacionalidades en España, Madrid, Casa de Velázquez, 2007; 3-10.

Serrano, Carlos, El nacimiento de Carmen: símbolos, mitos, nación, Madrid, Taurus, 1999.

Sorlin, Pierre, Italian National Cinema, Nueva York, Routledge, 1996.

Storm, Eric, "Regionalism in History, 1890-1945: the cultural approach”, European History Quaterly, 33/2, (Londres, 2003): 251-265.

Storm, Eric, The Culture of Regionalism. Art, Architecture and international exhibitions in France, Germany and Spain, 1890-1939, Manchester-Nueva York, Manchester University Press, 2010.

Steingress, Gerhard y Baltanás, Enrique (coords), Flamenco y nacionalismo. Aportaciones para una sociología política del flamenco, Sevilla, Universidad de Sevilla/Fundación Machado, 1998.

Triana Toribio, Nuria, Spanish National Cinema, Londres, Routledge, 2003.

Varela, Javier, La novela de España. Los intelectuales y el problema español, Madrid, Taurus, 1999.

Villares, Ramón, “La «España regional». Cultura y nación”, en Ramón Villares y Javier Moreno, Historia de España. Restauración y Dictadura, Madrid, CríticaMarcial Pons, 2009; 177-242.

VVAA, Andalucía. Cinco miradas críticas y una divagación, Sevilla, Fundación José Manuel Lara, 2003.

Williams, Alan, "Introduction”, en Alan Williams (ed.), Film and nationalism, New Brunswick, Rutgers, 2002; 1-22.

Woods, Eva, "From rags to riches: the ideology of stardom in folkloric musical comedy films of the late 1930s and 1940s", en Antonio Lázaro-Reboll y Andrew Willis (eds.), Spanish Popular Cinema, Manchester, Manchester University Press, 2004; 40-59. 
Yuval-Davies, Nira, Gender and Nation, Londres, Sage, 1997.

Zumalde, Imanol, “La Dolorosa”, en Julio Pérez Perucha (ed.), Flor en sombra. Antología crítica del cine español, Madrid, Cátedra, 1997; 92-94.

Zunzunegui, Santos, Euzkadi. Un film de Teodoro Ernandorena (1933-1983), Bilbao, Caja de Ahorros Vizcaína, 1983.

Recibido: 21-06-2011

Aceptado: 27-10-2011 